\title{
Optic pathway glioma and the sex association in neurofibromatosis type 1: a single-center study
}

\author{
Anne Munk Henning ${ }^{1 *}\left(\mathbb{D}\right.$, Mette Møller Handrup ${ }^{1}$, Sia Mariann Kjeldsen², Dorte Ancher Larsen² and \\ Cecilie Ejerskov ${ }^{1,3}$
}

\begin{abstract}
Background: Low-grade optic pathway glioma (OPG) develops in 15-20\% of children with neurofibromatosis type 1 (NF1). OPGs are symptomatic in 30-50\% and one-third of these require treatment. A few studies have suggested female sex as a risk factor for visual impairment associated with NF1-OPG. This descriptive study investigated the correlation between NF1-OPG growth, sex and visual impairment.
\end{abstract}

Method: We based our cross-sectional study on a systematic, retrospective data collection in a NF1 cohort of children and adolescents below 21 years of age followed at Center for Rare Diseases, Aarhus University Hospital, Denmark. For each patient with OPG a medical chart review was performed including demographics, ophthalmological examinations and magnetic resonance imaging (MRI) of OPG.

Results: Of 176 patients with NF1 (85 females, 91 males), we identified 21 patients with OPG (11.9\%) with a preponderance of females, $p=0.184$. Eight females (62\%) and one male (13\%) had visual impairment at the last ophthalmological evaluation. Five out of 21 children with OPG (24\%) underwent diagnostic MRI because of clinical findings at the ophthalmological screening. Nine children (43\%) had symptoms suggestive of OPG and seven (33\%) experienced no OPG-related symptoms before the diagnostic MRI. Of eight children diagnosed with OPG $\leq$ two years of age, one had visual impairment. Of 13 children diagnosed > two years of age, eight had visual impairment; in each group, four of the children were treated with chemotherapy. The study suggested no correlation between NF1-OPG growth and sex.

Conclusion: Our data suggest sex as a risk factor for visual impairment, while an OPG diagnose $\leq$ two years of age was a protective factor for visual impairment. Females with NF1-OPG had a higher prevalence of visual impairment outcome compared to males. Interestingly, our data also suggest a better response to treatment in children with OPG diagnosed $\leq$ two years of age compared to older children. The findings in our study suggest sex as a potential prognostic factor for visual impairment.

Keywords: Neurofibromatosis type 1, Optic pathway glioma, Sex characteristics, Ophthalmological screening

\footnotetext{
*Correspondence: anuhen@rm.dk

${ }^{1}$ Center for Rare Diseases, Department of Pediatrics and Adolescent

Medicine, Aarhus University Hospital, Palle Juul-Jensens, Boulevard 99, 8200 Aarhus N, Denmark

Full list of author information is available at the end of the article
}

\section{Background}

Neurofibromatosis type 1 (NF1) is a complex autosomal dominant disorder caused by germline pathogen variations in the NF1 tumor suppressor gene $[1,2]$. NF1 is a rather common rare disease, and the incidence is one case per 2500-3000 individuals worldwide [2, 3]. original author(s) and the source, provide a link to the Creative Commons licence, and indicate if changes were made. The images or other third party material in this article are included in the article's Creative Commons licence, unless indicated otherwise in a credit line to the material. If material is not included in the article's Creative Commons licence and your intended use is not permitted by statutory regulation or exceeds the permitted use, you will need to obtain permission directly from the copyright holder. To view a copy of this licence, visit http://creativecommons.org/licenses/by/4.0/. The Creative Commons Public Domain Dedication waiver (http://creativecommons.org/publicdomain/zero/1.0/) applies to the data made available in this article, unless otherwise stated in a credit line to the data. 
Approximately $15-20 \%$ of children with NF1 develop a benign, low-grade optic pathway glioma (OPG) [3, 4]. In the majority of children the OPG is diagnosed before seven years of age (mean 4.5 years) [5]. The OPGs are symptomatic in $30-50 \%$ of the children causing mainly vision loss and endocrine abnormalities. One-third of OPGs require therapeutic intervention due to visual impairment or increase of OPG on imaging $[4,5]$. Treatment of NF1-OPGs is primarily reserved for patients with progressive clinical symptoms and commonly involves chemotherapy [6].

Optic pathway glioma can develop anywhere along the optic pathway [7-9]. OPGs are generally slow growing benign tumors, but individual tumors can have dramatic variability in their growth pattern with periods of rapid growth, prolonged quiescence or spontaneous regression [10-12]. The tumor growth may result in unilateral exophthalmus, visual impairment, visual field defect and ophthalmological findings such as an afferent pupillary defect, optic nerve atrophy, defects in color vision, strabismus, papilledema or precocious puberty $[5,13]$. Magnetic resonance imaging (MRI) is the modality of choice for diagnostic purposes in NF1 patients with unexplained ophthalmological abnormalities [14-16].

Currently, our outpatient clinic at the Department of Ophthalmology, Aarhus University Hospital (AUH), performs an ophthalmological screening every six month until the age of eight years, and an annual screening from eight to 12 years of age. Ophthalmological examinations including age specific monitoring of NF1-OPG manifestations are important, as risk factors for visual impairment are a diagnosis of OPG below the age of two years, tumor involvement of the posterior optic tract and germline NF1 pathogenic variations $[3,17,18]$.

In July 2020, we performed a literature search in the databases PubMed and EMBASE to research if sex could be a potential risk factor for visual impairment. The inclusion criteria were: (1) Case reports or case series describing the potential role of sex as a clinically relevant modifier for symptoms caused by OPG in children with NF1, (2) studies researching the responsible etiology behind potential sex characteristics and OPG associated to NF1 and (3) reviews of NF1-OPG focusing on clinical manifestations and risk modifiers such as the sex of the patient. The search identified five articles: two clinical studies, two experimental studies and one article that included both a clinical and an experimental part [1923]. Of the clinical studies, two studies presented a significant overrepresentation of females with NF1 developing OPGs $[19,20]$. One study found that females were twice as likely to undergo brain MRI for visual symptoms and three times more likely to require treatment due to visual impairment than their male counterparts [21].
The aim of this study was to further investigate the correlation between NF1-OPG growth, visual impairment and sex to optimize screening guidelines for OPG in children with NF1.

\section{Methods \\ The NF1-OPG cohort}

We included children with NF1-associated OPG born between January 2000 and January 2020 referred to Center for Rare Diseases (CRD), Department of Pediatrics and Adolescent Medicine, AUH, one of two Danish national specialist centers for NF1 with West Denmark as catchment area. The center monitors patients with NF1 from infancy until older age, regardless of severity of disease and socioeconomic background as the public Danish healthcare system is tax-financed. The children met the clinical diagnosis of NF1 according to established international criteria [24].

\section{Protocol}

We conducted a small cross-sectional study based on retrospective data from the medical charts of patients with OPG. Patients were included if they had a confirmed clinical diagnosis of NF1, a follow-up at CRD after two years of age and OPG. An initial screening of the medical charts was performed to identify the patients for inclusion. A medical chart review was then performed, and data were collected for each patient with a diagnosis of OPG. The data included information about demographic characteristics: sex, age at study inclusion, age at OPG diagnosis, indication for OPG diagnostic MRI, OPG location, ophthalmic examinations evaluating developmental change of visual impairment, MRI descriptions on tumor growth and potential treatment.

We defined the children's visual acuity based on their inferior eye to evaluate the effect of the OPG on sight. Visual acuity was divided into two categories: Normal vision and Visual impairment. Visual impairment was defined as a Snellen visual acuity below 0.63 for children up to five years of age, while children six years or older had Visual impairment with a Snellen visual acuity below 0.80 . A visual acuity above 0.63 and 0.80 for age, respectively, was defined as Normal vision. A difference in two lines or more on the eye chart between the inferior and the superior eye was categorized as Visual impairment.

The location of the OPG was defined from the diagnostic MRI, and progression tendency was defined from the last MRI description on OPG growth.

Informed consent was obtained from included patients and parents in cases of under aged patients with a diagnosis of OPG. Only data from medical charts on the included patients were available. Personal identifiable data have been omitted from this study. The study was 
approved by the Danish Data protection Agency. According to the Ethics Committee of Denmark, no approval was needed for this retrospective database investigation.

\section{Data analysis}

A data project was created in the Research Electronic Data Capture (REDCap) to collect and manage data. REDCap is a secure web-based platform designed to virtually capture data for research studies and can provide automated export functions for data downloads internationally $[25,26]$.

\section{Statistical analyses}

Descriptive statistics for the main variables of interest were calculated using proportions for categorical data and means, medians and ranges for continuous data. Statistical analyses were performed in Maplesoft. The Chi square test was used if all of the expected numbers were higher than five. If an expected number was less than five, statistics were not calculated because of the small data collection and the risk of chance findings. A $p$ value $<0.05$ was considered statistically significant.

\section{Results}

\section{The CRD-OPG cohort}

A total of 180 patients were screened and 176 patients with NF1 (48.3\% females and 51.7\% males) were eligible for inclusion (Fig. 1).

Table 1 presents the initial screening of the CRD patients and the included CRD-OPG cohort. In total 21 children (11.9\%) were identified with OPG and included in the study; thirteen females (15.3\%) and eight males $(8.8 \%)$ out of the 176 children had OPG. There was a preponderance of females with OPG, $p=0.184$. The follow-up time was calculated from the date of the OPG diagnosis to the date of the last ophthalmological evaluation.

\section{The diagnostic MRI-indications}

Table 2 presents the different indications for diagnostic MRIs. Five out of 21 children with OPG (24\%) underwent a diagnostic brain MRI based on clinical findings at the ophthalmological screening; in three of the four children with a unilateral change in color or shape of the optic disc, the diagnostic MRI showed an OPG in the opposite eye. In nine out of the 21 children (43\%) the indication for a diagnostic MRI was other symptoms suggestive of OPG. The symptoms were most often noticed by the parents. Five of the children with other symptoms suggestive of OPG were diagnosed with NF1 and OPG at the same time, and they did not follow the ophthalmological screening program before their MRI. Seven children

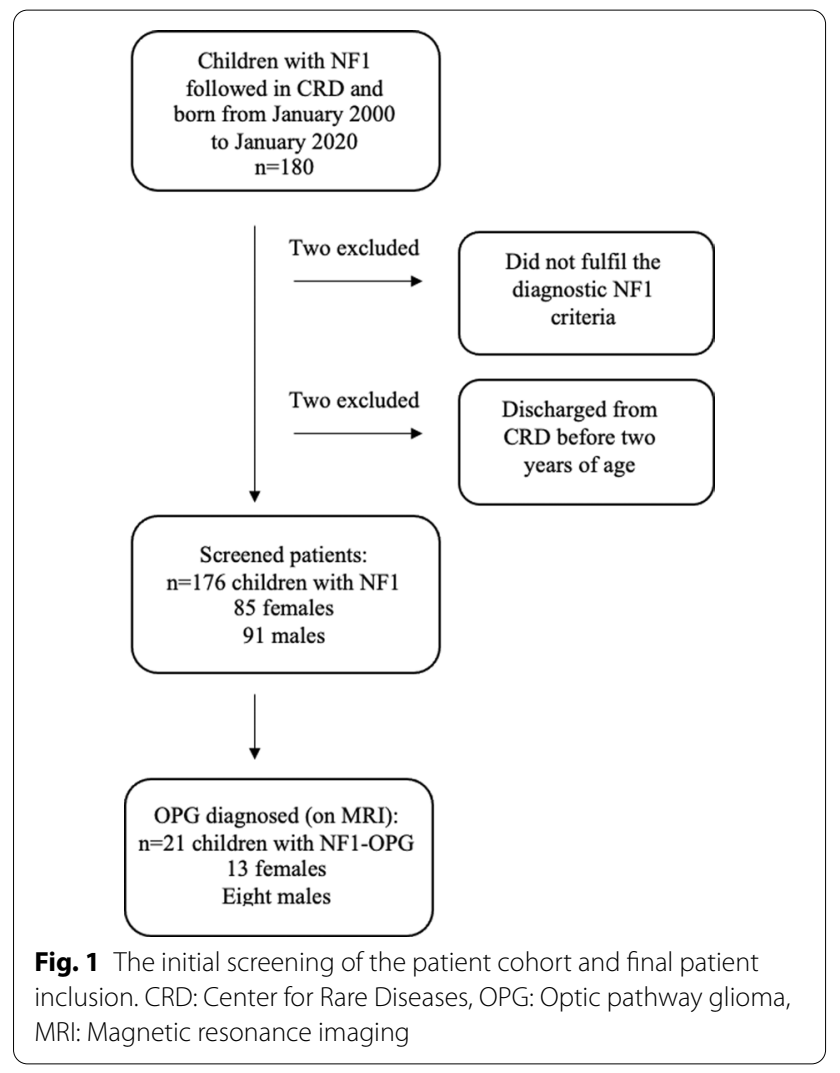

Table 1 Demographics of children with OPG

\begin{tabular}{|c|c|c|c|}
\hline & Females & Males & Total \\
\hline Children with NF1, n (\%) & $85(48.3)$ & $91(51.7)$ & $176(100.0)$ \\
\hline $\begin{array}{l}\text { Median age at study inclusion, year, } \\
\text { range }\end{array}$ & $12[6-20]$ & $10[5-18]$ & $11[5-20]$ \\
\hline \multicolumn{4}{|l|}{ Age at $O P G$ diagnosis } \\
\hline$\leq 2$ years old, year (\%) & $4(31)$ & $4(50)$ & $8(38)$ \\
\hline 2-5 years old, year (\%) & $4(31)$ & $1(13)$ & $5(24)$ \\
\hline$\geq 5$ years old, year (\%) & $5(39)$ & $3(38)$ & $8(38)$ \\
\hline Median age, year, range & $5[1-13]$ & $3[2-7]$ & $4[1-13]$ \\
\hline \multicolumn{4}{|l|}{ Follow-up from OPG diagnosis } \\
\hline Median duration, year, range & $7[2-13]$ & $6[0-16]$ & $7[0-16]$ \\
\hline
\end{tabular}

*OPG: Optic pathway glioma

(33\%) experienced no OPG-related symptoms before MRI was performed.

OPG location, visual outcome, progression and treatment The OPG location, visual outcome, progression and treatment are presented in Table 3. In females, the OPG mostly involved the optic nerves (62\%); in males, the chiasma or anterior/posterior pathway were mostly involved (63\%). Of the 11 patients with OPG of the optic nerve, four $(36 \%)$ had visual impairment. Five (50\%) had visual 
Table 2 Indication for OPG diagnostic MRI

\begin{tabular}{|c|c|c|c|}
\hline & Females n: 13 (\%) & Males n: 8 (\%) & Total n: 21 (\%) \\
\hline \multicolumn{4}{|l|}{ Ophthalmological screening } \\
\hline Total, n (\%) & $3(23 \%)$ & $2(25 \%)$ & $5(24 \%)$ \\
\hline Optic disc*, unilateral & 2 & 2 & 4 \\
\hline Reduced visual acuity & 1 & & 1 \\
\hline \multicolumn{4}{|l|}{ Other symptoms suggestive of $O P G$} \\
\hline Total, n (\%) & $5(38 \%)$ & $4(50 \%)$ & $9(43 \%)$ \\
\hline Change in visual behavior & 1 & 1 & 2 \\
\hline Strabismus & 1 & & 1 \\
\hline Exophthalmus & 1 & 1 & 2 \\
\hline Macrocephaly & & 2 & 2 \\
\hline Hydrocephalus & 1 & & 1 \\
\hline Growth retardation & 1 & & 1 \\
\hline \multicolumn{4}{|l|}{ No OPG-related symptoms } \\
\hline Total, n (\%) & $5(38 \%)$ & $2(25 \%)$ & $7(33 \%)$ \\
\hline $\begin{array}{l}\text { Routine brain MRI at diagnosis or as part of surveil- } \\
\text { lance }\end{array}$ & 5 & 2 & 7 \\
\hline
\end{tabular}

OPG: Optic pathway glioma

MRI: Magnetic resonance imaging

${ }^{*}$ Change in color (pale) or shape of the optic disc

Table 3 OPG Location, treatment, progression and visual outcome

\begin{tabular}{|c|c|c|c|}
\hline & $\begin{array}{l}\text { Females n: } 13 \\
\text { (\%) }\end{array}$ & Males n: 8 (\%) & Total n: 21 (\%) \\
\hline \multicolumn{4}{|l|}{ Location } \\
\hline Optic nerves & $8(62 \%)$ & $3(38 \%)$ & $11(52 \%)$ \\
\hline $\begin{array}{l}\text { Chiasma } \pm \text { ante- } \\
\text { rior/posterior } \\
\text { pathway }\end{array}$ & $5(38 \%)$ & $5(63 \%)$ & $10(48 \%)$ \\
\hline \multicolumn{4}{|l|}{ Visual outcome } \\
\hline Normal & $5(38 \%)$ & $7(88 \%)$ & $12(57 \%)$ \\
\hline Visual impairment & $8(62 \%)$ & $1(13 \%)$ & $9(43 \%)$ \\
\hline \multicolumn{4}{|c|}{ Progression (tendency) } \\
\hline Stable & $9(69 \%)$ & $3(60 \%)$ & $12(67 \%)$ \\
\hline $\begin{array}{l}\text { Radiological } \\
\text { regression }\end{array}$ & $2(15 \%)$ & $2(40 \%)$ & $4(22 \%)$ \\
\hline $\begin{array}{l}\text { Radiological } \\
\text { progression }\end{array}$ & $2(15 \%)$ & & $2(11 \%)$ \\
\hline \multicolumn{4}{|l|}{ Treatment ${ }^{*}$} \\
\hline Untreated & $7(54 \%)$ & $6(75 \%)$ & $13(62 \%)$ \\
\hline Treated & $6(46 \%)$ & $2(25 \%)$ & $8(38 \%)$ \\
\hline
\end{tabular}

OPG: Optic pathway glioma

*The mainstay of treatment: Chemotherapy

impairment of the 10 patients with OPG involving chiasma \pm anterior/posterior pathway.

Eight of the female children (62\%) were categorized as having visual impairment at their latest ophthalmological evaluation; this was only found in one (13\%) of the male patients. In two females, tumor progression was described at the latest MRI. Radiological tumor progression was not found in any of the male children, but data on three males $(38 \%)$ were missing since only on MRI had been performed.

Generally, treatment was initiated if ophthalmological findings showed decreased visual acuity and/or radiological evidence of growth, although the approach varied. In total, six females (46\%) and two males (25\%) were treated with a standardized chemotherapy regimen according to the then international protocol on OPG. Of the eight treated patients, one girl and one boy required radiation and one girl required surgery in addition to chemotherapy and targeted therapy (MEK-inhibitor Trametinib). Radiation, surgery and targeted therapy were initiated due to tumor progression identified radiologically or decreased visual acuity after chemotherapy was completed.

Treatment was required in four children diagnosed $>$ two years of age. They started treatment at the age range from four to 13 years, and all had visual impairment at the last ophthalmological evaluation. Eight children were diagnosed with $\mathrm{OPG} \leq$ two years old; five were diagnosed without having any symptoms suggesting OPG, one was diagnosed because of change in the optic disc but had OPG on the opposite eye, and two children experienced symptoms related to their tumors (hydrocephalus and exophthalmus). Among 
the eight children $\leq$ two years old at diagnosis, one was defined as having visual impairment, whereas eight out of 13 patients > two years of age at their OPG diagnosis were found to have visual impairment. Children diagnosed $\leq$ two years of age had 8.7 years' follow-up, and our data suggest that they were less likely to have visual impairment than children diagnosed $>$ two years of age. Four of the children diagnosed with OPG $\leq$ two years of age required treatment; three started treatment at the age range two to four years and had normal visual acuity at the last ophthalmological evaluation and one started treatment at the age of seven years and had visual impairment at the last ophthalmological evaluation.

\section{Discussion}

This study is the first to investigate a potential association between NF1-OPG growth, visual impairment and sex within a Danish NF1 cohort. Firstly, our data suggest a correlation between the sex and visual impairment in patients below 21 years of age with NF1-OPG as females were more likely to have visual impairment than their male counterparts in our cohort. This is in line with a study by Diggs-Andrews et al [21]. Within our NF1cohort, our results suggest that females with OPGs could require treatment more often than the males. However, our cohort was small, and chance findings are possible. OPG occurred more often in females compared to the males in our cohort; this difference was not significant. Furthermore, our study did not find that the OPG location played an important role in dictating the visual acuity. Tumor progression was only found in two females; however, radiological data were not available for three males, which made it difficult to identify potential associations to NF1-OPG growth.

Secondly, our data suggest that children $\leq$ two years of age were less likely to have visual impairment despite a longer follow-up time. This is in contrast to previous literature reporting a diagnosis of OPG before the age of two years as a risk factor for vision loss $[3,18,27]$. However, it has been suggested that the focus of most previous reports has been on radiographic changes and treatment strategies [28]. Still, in our study the children diagnosed $\leq$ two years of age were not identified at visual acuity examinations, which seem to be the most reliable screening test and risk factor for visual impairment [9, 29-31]. This is likely to bias the results and could explain why they had a better visual outcome compared to the older children in the cohort. Unfortunately, it is difficult to examine the visual acuity in young children and MRI is more easily performed on clinical suspicion, which could lead to detection of more asymptomatic OPGs. Still, screening baseline brain MRI evaluations in children with NF1 are not advocated, as the detection of OPG rarely changes management in the absence of symptoms.

Thirdly, within our cohort five of the OPGs were diagnosed due to clinical findings at the ophthalmological screening; four cases were due to change in the color or shape of the optic disc. Interestingly, three of the four children had OPG on the opposite eye than expected from the screening, which could question the accuracy and sensitivity of the ophthalmological screening methods and strategy. Moreover, whether these ophthalmological findings were due to symptomatic OPGs is questionable and if the aim of the screening was to detect all OPGs MRI would be the method of choice $[15,32]$. Visual acuity testing can be difficult and unreliable in young children, and the child's ability to cooperate is crucial. Still, literature supports that visual acuity testing is the most reliable indicator of a symptomatic OPG [5, 30, 31]. A recent study by Kinori et al. found not only visual acuity, but also optic disc appearance (pale or edematous) as strong predictors of poor visual outcomes in 45 children with NF1-OPG [28]. This was not shown in our study and may be due to the lack of accuracy of the ophthalmological screening methods or coincidental due to the small cohorts in both studies. Hence, more research is needed on reliable indicators of a symptomatic OPG.

Our literature search identified three articles on exploring the pathogenesis behind the possible sexual dimorphism [21-23]. Fisher, M. J., et al. studied visual outcomes in children with NF1-OPG following chemotherapy [33]. They did not find that sex was a prognostic factor for visual outcome in the treated population, but they reported a disproportionate number of females with OPG requiring treatment compared to the males, $p=0.0075$ [33]. This might indicate that there is no correlation between sex and response to treatment and that females might have worse OPG symptoms compared to males. This sexual dimorphism has been explored in $\mathrm{Nf1}$ mutant mice, where only female mice presented reduced visual acuity from their OPG despite equal tumor volumes and proliferative indices [21]. Research has suggested that the dimorphism can result from estrogen activation of microglia in female Nf1 mice [23]. Another study found a sex specific role for cAMP regulation in gliomagenesis in patients with NF1, specifically identifying ADCY8 elevating the OPG risk in females and decreasing risk in males 22 . The sexual dimorphism is in line with what was found in our study.

Interestingly, our study showed that in the treated children diagnosed with OPG $\leq$ two years of age only one child had a visual impairment at the last ophthalmological examination (25\%). The treated children diagnosed with OPG > two years of age all had visual impairment (100\%). The three treated children with normal vision all 
started treatment at four years of age or earlier, whereas the treated children with visual impairment started treatment between four and 13 years of age. This could indicate that treatment response is associated with the age of the patient and highlights the importance of agespecific monitoring of NF1-OPG manifestations. Further research is needed to investigate the potential correlation.

Our retrospective study has some limitations. As the study involves patients with a rare disease, the patient population was small which limited the statistical analyses. In small studies, there is a risk of the results to be chance findings. The OPG frequency of $11.9 \%$ is a crosssectional proportion as some children can still develop OPG in the future or may already have an asymptomatic OPG. It would have been interesting to view the numbers and results of cerebral MRI in the non-OPG patients within our cohort, but due to ethics of the study we were only able to review and use data from the medical charts of patients with a diagnosis of OPG. The number of patient non-appearances at appointments caused missing data in our cohort resulting in a risk of limitation to the study result. Furthermore, five patients were diagnosed with OPG at the same time as diagnosed with NF1; therefore, they did not follow the ophthalmological screening program. If they had been enrolled in the ophthalmological screening program, the OPG might have been detected at an earlier stage, and their visual outcomes could have been different. It was also difficult to register tumor progression due to the lack of consensus regarding the specific interval of neuroimaging of already identified OPGs. The tumor sizes were not examined and therefore not available in this study, but the association between size and visual impairment would be interesting for future studies. The ophthalmological examinations used different tools to evaluate the visual acuity in accordance with the age of the child, which could affect the result of their last ophthalmological examination and our definition of Normal or Visual impairment. Furthermore, the screening strategy in OPG and indication of MRI varied among physicians.

\section{Conclusion}

In conclusion, our study suggests sex as a risk factor for visual impairment, while an OPG diagnosis $\leq$ two years of age was a protective factor for visual impairment. We found that females with NF1-OPG had a higher prevalence of visual impairment outcome compared with males, this was in accordance with existing literature. Furthermore, our study found an OPG prevalence of $11.9 \%$ in patients below 21 years in our children and youth cohort with a preponderance of females (15.3\%). We found no correlation between NF1-OPG growth and sex. The findings in our study suggest sex as a potential prognostic factor for visual impairment. Interestingly, our data also suggest a better response to treatment in children with OPG diagnosed $\leq$ two years of age compared to older children. However, our cohort was small, and more research is needed to determine not only sex but also other potential risk factors for NF1-OPG associated visual impairment to optimize screening guidelines for OPG in children with NF1.

\section{Acknowledgements \\ None. \\ Authors' contributions \\ Conception and design: all authors. Data collection: AMH. Data analysis and interpretation: all authors. Manuscript writing: $\mathrm{AMH}$ and CE. Final approval of manuscript: all authors. All authors read and approved the final manuscript. \\ Funding \\ None. \\ Availability of data and materials \\ Could be available from the corresponding author on reasonable request.}

\section{Declarations}

Ethics approval and consent to participate

Informed consent was obtained from included patients and parents in cases with underaged patients. The study was approved by the Danish Data protection Agency. According to the Ethics Committee of Denmark, no approval was needed for this retrospective databased investigation.

\section{Consent for publication}

Personal identifiable data have been omitted from the manuscript.

\section{Competing interests}

None.

\section{Author details}

${ }^{1}$ Center for Rare Diseases, Department of Pediatrics and Adolescent Medicine, Aarhus University Hospital, Palle Juul-Jensens, Boulevard 99, 8200 Aarhus N, Denmark. ${ }^{2}$ Department of Ophthalmology, Aarhus University Hospital, Palle Juul-Jensens Boulevard 167, 8200 Aarhus N, Denmark. ${ }^{3}$ Department of Clinical Medicine, Aarhus University, Aarhus, Denmark.

Received: 27 April 2021 Accepted: 6 November 2021

Published online: 22 November 2021

\section{References}

1. Huson, S. M., Compston, D. A., Clark, P., Harper, P. S. A genetic study of von Recklinghausen neurofibromatosis in south east Wales I Prevalence, fitness, mutation rate, and effect of parental transmission on severity. J Med Genet 26, 704-711, https://doi.org/10.1136/jmg.26.11.704 (1989).

2. Rasmussen SA, Friedman JM. NF1 gene and neurofibromatosis 1. Am J Epidemiol. 2000;151:33-40. https://doi.org/10.1093/oxfordjournals.aje. a010118.

3. Campen CJ, Gutmann DH. Optic pathway gliomas in neurofibromatosis type 1. J Child Neurol. 2018;33:73-81. https://doi.org/10.1177/08830 73817739509.

4. Lewis RA, Gerson LP, Axelson KA, Riccardi VM, von Whitford RP. Recklinghausen neurofibromatosis II Incidence of optic gliomata. Ophthalmology. 1984;91:929-35. https://doi.org/10.1016/s0161-6420(84)34217-8.

5. Listernick R, Ferner RE, Liu GT, Gutmann DH. Optic pathway gliomas in neurofibromatosis-1: controversies and recommendations. Ann Neurol. 2007;61:189-98. https://doi.org/10.1002/ana.21107. 
6. Mahoney DH Jr, et al. Carboplatin is effective therapy for young children with progressive optic pathway tumors: a Pediatric Oncology Group phase II study. Neuro Oncol. 2000;2:213-20. https://doi.org/10.1093/ neuonc/2.4.213.

7. Listernick R, Charrow J, Greenwald MJ, Esterly NB. Optic gliomas in children with neurofibromatosis type 1. J Pediatr. 1989;1 14:788-92. https:// doi.org/10.1016/s0022-3476(89)80137-4.

8. Listernick R, Darling C, Greenwald M, Strauss L, Charrow J. Optic pathway tumors in children: the effect of neurofibromatosis type 1 on clinical manifestations and natural history. J Pediatr. 1995;127:718-22. https://doi. org/10.1016/s0022-3476(95)70159-1.

9. Segal L, Darvish-Zargar M, Dilenge ME, Ortenberg J, Polomeno RC. Optic pathway gliomas in patients with neurofibromatosis type 1: follow-up of 44 patients. J aapos. 2010;14:155-8. https://doi.org/10.1016/j.jaapos.2009. 11.020 .

10. de Blank PMK, et al. Optic pathway gliomas in neurofibromatosis type 1: an update: surveillance, treatment indications, and biomarkers of vision. J Neuroophthalmol. 2017;37(Suppl 1):S23-s32. https://doi.org/10.1097/ wno. 0000000000000550 .

11. Piccirilli M, et al. Spontaneous regression of optic pathways gliomas in three patients with neurofibromatosis type I and critical review of the literature. Childs Nerv Syst. 2006;22:1332-7. https://doi.org/10.1007/ s00381-006-0061-3.

12. Liu GT. Optic gliomas of the anterior visual pathway. Curr Opin Ophthalmol. 2006;17:427-31. https://doi.org/10.1097/01.icu.0000243016.90004. 12.

13. Habiby R, Silverman B, Listernick R, Charrow J. Precocious puberty in children with neurofibromatosis type 1. J Pediatr. 1995;126:364-7. https:// doi.org/10.1016/s0022-3476(95)70449-3.

14. King, A., Listernick, R., Charrow, J., Piersall, L. \& Gutmann, D. H. Optic pathway gliomas in neurofibromatosis type 1: the effect of presenting symptoms on outcome. Am J Med Genet A 122a, 95-99, doi:https://doi. org/10.1002/ajmg.a.20211 (2003).

15. Listernick R, Louis DN, Packer RJ, Gutmann DH. Optic pathway gliomas in children with neurofibromatosis 1: consensus statement from the NF 1 Optic Pathway Glioma Task Force. Ann Neurol. 1997;41:143-9. https://doi. org/10.1002/ana.410410204.

16. Cassiman C, Legius E, Spileers W, Casteels I. Ophthalmological assessment of children with neurofibromatosis type 1. Eur J Pediatr. 2013;172:132733. https://doi.org/10.1007/s00431-013-2035-2.

17. Toonen JA, et al. NF1 germline mutation differentially dictates optic glioma formation and growth in neurofibromatosis-1. Hum Mol Genet. 2016;25:1703-13. https://doi.org/10.1093/hmg/ddw039.

18. Laithier $\mathrm{V}$, et al. Progression-free survival in children with optic pathway tumors: dependence on age and the quality of the response to chemotherapy-results of the first French prospective study for the French Society of Pediatric Oncology. J Clin Oncol. 2003;21:4572-8. https://doi. org/10.1200/jco.2003.03.043.

19. Robert-Boire V, Rosca L, Samson Y, Ospina LH, Perreault S. Clinical presentation and outcome of patients with optic pathway glioma. Pediatr Neurol. 2017;75:55-60. https://doi.org/10.1016/j.pediatrneurol.2017.06. 019.
20. Trevisson E, et al. Natural history of optic pathway gliomas in a cohort of unselected patients affected by Neurofibromatosis 1. J Neurooncol. 2017;134:279-87. https://doi.org/10.1007/s11060-017-2517-6.

21. Diggs-Andrews KA, et al. Sex Is a major determinant of neuronal dysfunction in neurofibromatosis type 1. Ann Neurol. 2014;75:309-16. https://doi. org/10.1002/ana.24093.

22. Warrington NM, et al. The cyclic AMP pathway is a sex-specific modifier of glioma risk in type I neurofibromatosis patients. Can Res. 2015;75:16-21. https://doi.org/10.1158/0008-5472.CAN-14-1891.

23. Toonen JA, Solga AC, Ma Y, Gutmann DH. Estrogen activation of microglia underlies the sexually dimorphic differences in Nf1 optic glioma-induced retinal pathology. J Exp Med. 2017;214:17-25. https://doi.org/10.1084/ jem.20160447.

24. Stumpf, D. Neurofibromatosis. Conference statement. National institutes of health consensus development conference. Arch Neurol 45, 575-578 (1988).

25. Harris PA, et al. Research electronic data capture (REDCap)-a metadatadriven methodology and workflow process for providing translational research informatics support. J Biomed Inform. 2009;42:377-81. https:// doi.org/10.1016/j.jbi.2008.08.010.

26. Harris PA, et al. The REDCap consortium: Building an international community of software platform partners. J Biomed Inform. 2019;95: 103208. https://doi.org/10.1016/j.jbi.2019.103208.

27. Gutmann DH, et al. Neurofibromatosis type 1. Nat Rev Dis Primers. 2017;3:17004. https://doi.org/10.1038/nrdp.2017.4.

28. Kinori M, Armarnik S, Listernick R, Charrow J, Zeid JL. Neurofibromatosis Type 1-associated optic pathway glioma in children: a follow-up of 10 years or more. Am J Ophthalmol. 2021;221:91-6. https://doi.org/10. 1016/j.ajo.2020.03.053.

29. Caen, S., Cassiman, C., Legius, E. \& Casteels, I. Comparative study of the ophthalmological examinations in neurofibromatosis type 1. Proposal for a new screening algorithm. Eur J Paediatr Neurol 19, 415-422, doi:https:// doi.org/10.1016/j.ejpn.2015.03.002 (2015).

30. Listernick R, Charrow J, Gutmann DH. Comments on neurofibromatosis 1 and optic pathway tumors. Am J Med Genet. 2001;102:105. https://doi. org/10.1002/1096-8628(20010722)102:1\%3c105:aid-ajmg1395\%3e3.0. co; 2 -c.

31. Avery RA, Fisher MJ, Liu GT. Optic pathway gliomas. J Neuroophthalmol. 2011;31:269-78. https://doi.org/10.1097/WNO.0b013e31822aef82.

32. Gutmann, D. H., Listernick, R. \& Ferner, R. E. Screening for symptomatic optic pathway glioma in children with neurofibromatosis type 1. Eye (Lond) 25, 818; author reply 818-819, doi:https://doi.org/10.1038/eye. 2010.227 (2011).

33. Fisher MJ, et al. Gender as a disease modifier in neurofibromatosis type 1 optic pathway glioma. Ann Neurol. 2014;75:799-800. https://doi.org/10. 1002/ana.24157.

\section{Publisher's Note}

Springer Nature remains neutral with regard to jurisdictional claims in published maps and institutional affiliations.

Ready to submit your research? Choose BMC and benefit from

- fast, convenient online submission

- thorough peer review by experienced researchers in your field

- rapid publication on acceptance

- support for research data, including large and complex data types

- gold Open Access which fosters wider collaboration and increased citations

- maximum visibility for your research: over $100 \mathrm{M}$ website views per year

At BMC, research is always in progress.

Learn more biomedcentral.com/submissions 